\title{
Oral and bronchial provocation tests with aspirin for diagnosis of aspirin-induced asthma
}

\author{
E. Niżankowska, A. Bestyńska-Krypel, A. Ćmiel, A. Szczeklik
}

Oral and bronchial provocation tests with aspirin for diagnosis of aspirin-induced asthma. E. Nizankowska, A. Bestyńska-Krypel, A. Cmiel, A. Szczeklik. (C)ERS Journals Ltd 2000. ABSTRACT: In 35 asthmatic patients with acetylsalicylic acid (aspirin; ASA) intolerance (AIA) and 15 asthmatics tolerating ASA well, the authors compared the diagnostic value of the placebo-controlled oral ASA versus inhaled L-lysine (L) ASA challenges.

All AIA subjects gave a history of asthmatic attacks following ingestion of ASA and in all of them the intolerance was confirmed by oral challenge test over the past $10 \mathrm{yrs}$. Doses of ASA increasing in geometric progression were used in oral tests 10-312 mg (cumulative dose $500 \mathrm{mg}$ ); in bronchial tests $0.18-115 \mathrm{mg}$ (cumulative dose $182 \mathrm{mg}$ ). Either challenge was considered as positive, if forced expiratory volume in one second (FEV1) dropped at least $20 \%$ from the baseline value and/or strong extrabronchial symptoms of intolerance occurred. Urinary leukotriene $\mathbf{E}_{4}$ excretion was determined at baseline and following the challenges.

In 24 out of 35 patients the oral test was positive, based on a $20 \%$ decrease in FEV1. When including extrabronchial symptoms this was positive in 31 cases. Bronchial LASA challenge led to $\geq 20 \%$ fall FEV1 in 21 out of 35 cases, and in 27 cases when including extrabronchial symptoms. No correlation was observed between ASA provocative dose causing a $20 \%$ fall in FEV1, determined by the oral route compared to the inhalation route. Urinary $\mathrm{LTE}_{4}$ increased after both challenges the rise being higher following oral as compared to inhalation provocation $(p=0.0001)$.

It is concluded that both tests had similar specificity whilst the oral test showed a tendency to higher sensitivity for the clinical diagnosis of acetylsalicylic acid intolerance. The inclusion of extrabronchial symptoms into the criteria of test positivity enhanced the diagnostic value of both procedures. In both tests the highest leukotriene $E_{4}$ increases were found in the presence of extrabronchial symptoms, suggesting the participation of tissues other than the lung in aspirin induced leukotriene $\mathbf{E}_{\mathbf{4}}$ release to urine.

Eur Respir J 2000; 15: 863-869.
Jagiellonian University School of Medicine, Dept of Medicine, Cracow, Poland

\section{Correspondence: A. Szczeklik}

Jagiellon-ian University School of Medicine

Dept of Medicine

Skawinska 8

31-066 Cracow

Poland

Fax: 48126565786

Keywords: Aspirin-induced asthma provocation tests with aspirin urinary leukotriene $\mathrm{E}_{4}$ excretion

Received: July 201999

Accepted after revision January 312000
Acetylsalicylic acid (aspirin; ASA)-induced asthma (AIA) is a distinct clinical syndrome characterized by adverse respiratory reactions to ASA and other nonsteroidal anti-inflammatory drugs (NSAIDs) [1-4]. Subjects suffering from AIA frequently develop chronic rhinosinusitis with nasal polyps $[5,6]$. Following the ingestion of ASA and some NSAIDs bronchospasm occurs, often accompanied by extrabronchial symptoms like rhinorrhoea, nasal congestion, conjunctival irritation and scarlet flushing of the head and neck. In the majority of patients the first symptoms appear during the third or fourth decade of life. Asthma runs a protracted course despite the avoidance of ASA and other NSAIDs. While a patient's clinical history might give rise to the suspicion of AIA, the diagnosis can be established with certainty only by ASA challenge [3, 7-9]. There are three types of provocation tests, depending on the route of ASA administration: oral, bronchial (inhaled) and nasal. The protocols of provocation tests differ between various clinical centres [3, 4, 7-14]. The differences consist in dosing ASA, intervals separating the successive doses, and the criteria for the test positivity. It is therefore difficult to compare the results of the provocation tests, when performed according to various protocols.

The primary aim of the current study was to compare the diagnostic value of a simple and safe method of inhaled (bronchial) challenge test with L-lysine-ASA (L-ASA), with a modified method of oral ASA challenge test. The urinary excretion of cys-leukotrienes-(LTs), the mediators implied in the pathogenesis of AIA were also assessed [15-22].

\section{Material and methods}

\section{Patients}

Thirty-five patients with AIA (25 females and 10 males, mean age 43.9 yrs, range $27-70$ yrs) were studied. All gave a clear history of adverse reaction following the ingestion of ASA and in all of them the diagnosis of ASA intolerance was documented in the past by oral provocation test with the fall in forced expiratory volume in one second (FEV1) $\geq 20 \%$ as the positive criterion [9]. 
The control group consisted of 15 patients with bronchial asthma without ASA intolerance (ASA-tolerant asthmatics-ATA). There were 10 females and 5 males, mean age 36.5 yrs, range 21-44 yrs. All control asthmatics occasionally used aspirin and other NSAIDs without any adverse respiratory reactions. Some of the AIA and ATA patients participating in the study were on oral and/or inhaled glucocorticosteroids (GCS); a maximum dose of oral GCS did not exceed $10 \mathrm{mg}$ prednisolone [23]. Short-acting $\beta$-mimetics were stopped $8 \mathrm{~h}$ before the provocations, long-acting $\beta$-mimetics $24 \mathrm{~h}$ prior to the tests, theophilline $24-48 \mathrm{~h}$ before the test. Antihistamines were discontinued 1-2 weeks earlier, while astemizole - 6 weeks. Oral ASA and inhaled L-ASA challenges were always performed in patients with baseline FEV $1>60 \%$ of a predicted value and were separated by $\sim 2$-week intervals.

\section{Provocation procedures}

The study was carried out under a single-blind condition. Both tests were always preceded by a "placebo challenge" the day before the test proper. In both tests the geometric progression of ASA and L-ASA dose was used (fig. 1).

\section{Oral challenge test with acetylsalicylic acid}

Oral challenge was carried out on two consecutive days. On the first day, five capsules of placebo (sacharum lactis) were administered every $2.5 \mathrm{~h}$ (table 1 ); FEV1 values were allowed to vary by $<15 \%$ from baseline. If greater falls in FEV1 occurred, the patient was considered not to be in a stable clinical condition and was excluded from further testing. The actual test was performed during the second day according the following protocol (table 1).

The total cumulative dose of ASA was $500 \mathrm{mg}$ (table 1). During the challenge test with both placebo and ASA, pulmonary function tests (FEV1, forced vital capacity (FVC)) were carried out every $30 \mathrm{~min}$. This 2-day procedure was performed on patients hospitalized in the authors' Department. The patients were also observed for the following reactions: bronchial (bronchospasm, tightness of chest, wheezing), upper airway (rhinorrhoea, nasal congestion), and general reactions (ocular injection, periorbital swelling, erythema of the skin, the face and the upper thorax, etc.). The challenge procedure with ASA was interrupted, if a decrease of at least $20 \%$ in FEV1 was observed, or when strong extrabronchial symptoms (see below) appeared, or if the maximum cumulative dose of ASA has been reached.

\section{Inhaled lysine-acetylsalicylic acid challenge test}

L-ASA was administered by inhalation from a dosimeter-controlled jet nebulizer (Spire Electro 2; Respiratory Care Center, Hameenlinna, Finland) to the patients breathing through a mouthpiece, with a nose clip. By administering different solutions $(0.1 \mathrm{M}, 1 \mathrm{M}, 2 \mathrm{M})$ and by varying the number of breaths from the nebulizer, geometric progression in the cumulative doses of L-ASA was created (table 2). Fresh L-ASA solutions were prepared each day immediately before the start of the challenge by way of dissolving crystalline L-ASA (Aspisol, Horby AG, Germany) in $0.9 \%$ sodium chloride. The actual test with L-ASA was always preceded by "placebo challenge"
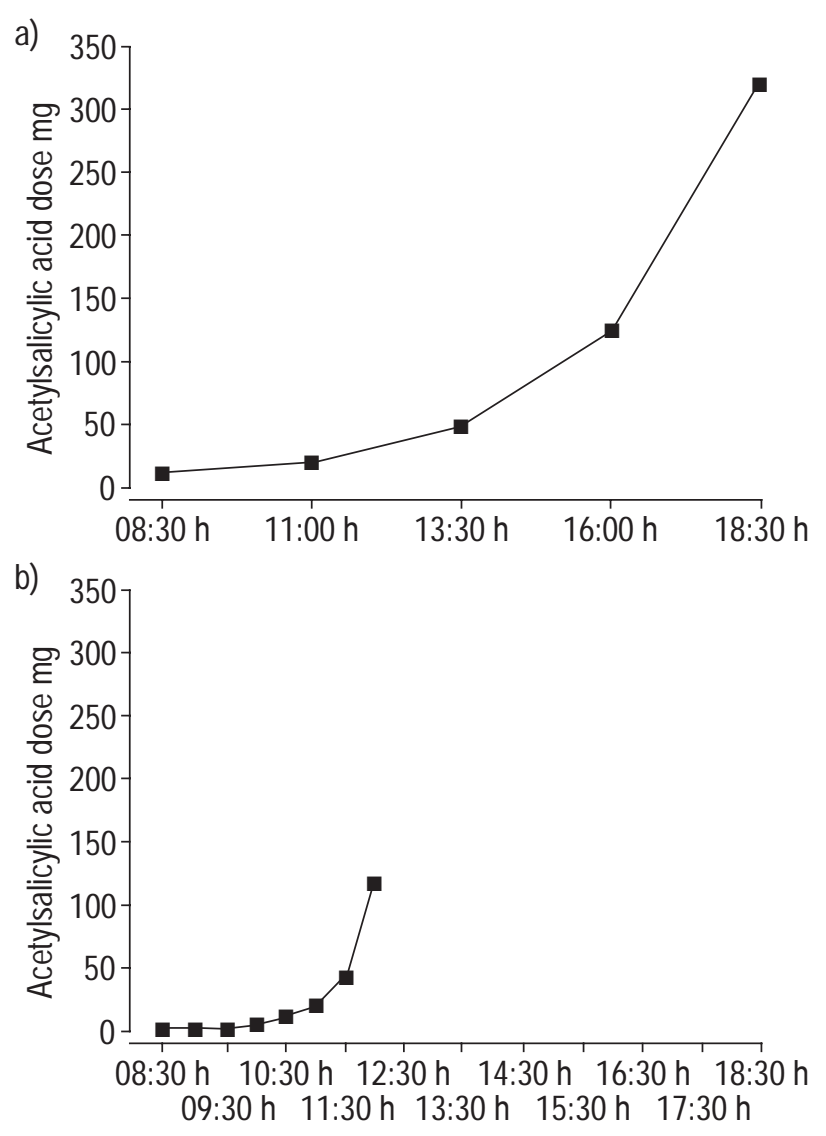

\section{Time of day}

Fig. 1. - a) dosing of acytylsalicylic acid (aspirin; ASA) in oral challenge test. Doses shown are: $10 ; 17 ; 44 ; 117$; and $312 \mathrm{mg}$, respectively. Maximal cumulative ASA dose was $500 \mathrm{mg}$. b) dosing of ASA in inhaled challenge test. Doses shown are: $0.18 ; 0.36 ; 0.90 ; 2.34 ; 7.20$; $16.20 ; 39.60 ; 115.20 \mathrm{mg}$, respectively. Maximal cumulative ASA dose was $182 \mathrm{mg}$.

the day before, when the patient inhaled a solution of lysine and glycine of the same $\mathrm{pH}$ and osmolarity, as in the solution of L-ASA and in the same manner (see below). The test with L-ASA began with the inhalation of $0.9 \%$ sodium chloride. Provided the postsaline FEV1 had not decreased after $20 \mathrm{~min}>10 \%$, the provocation with L-ASA was started. The consecutive doses of L-ASA

Table 1. - A two-day oral acetylsalicylic acid challenge test

\begin{tabular}{|c|c|c|c|}
\hline \multirow{2}{*}{$\begin{array}{l}\text { Time of drug } \\
\text { administration }\end{array}$} & \multirow[t]{2}{*}{ Day 1} & \multicolumn{2}{|c|}{ Day 2} \\
\hline & & $\begin{array}{l}\text { Consecutive } \\
\text { doses of ASA } \\
\text { administered }\end{array}$ & $\begin{array}{c}\text { Cumulative } \\
\text { doses of ASA } \\
\text { administered }\end{array}$ \\
\hline $08: 30 \mathrm{~h}$ & Placebo & $10(60)$ & $10(60)$ \\
\hline $11: 00 \mathrm{~h}$ & Placebo & 17 (102) & $27(162)$ \\
\hline $13.30 \mathrm{~h}$ & Placebo & $44(264)$ & $71(426)$ \\
\hline $16: 00 \mathrm{~h}$ & Placebo & $117(702)$ & $188(1128)$ \\
\hline $18: 30 \mathrm{~h}$ & Placebo & 312 (1872) & $500(3000)$ \\
\hline
\end{tabular}

Data are presented as absolute numbers in milligrams, with absolute values in micromoles in parentheses. ASA: acetylsalicylic acid (aspirin). 
Table 2. - Inhaled L-lysine (L) acetylsalicylic acid (aspirin; ASA) challenge test

\begin{tabular}{|c|c|c|c|c|c|c|}
\hline $\begin{array}{l}\text { Inhalation } \\
\text { series }\end{array}$ & $\begin{array}{c}\text { Solution of } \\
\text { L-ASA mmol }\end{array}$ & $\begin{array}{l}\text { No. of } \\
\text { breaths }\end{array}$ & $\begin{array}{l}\text { Inhaled dose } \\
\text { of ASA } \mu \text { mol }\end{array}$ & $\begin{array}{l}\text { Cumulative dose } \\
\text { of ASA } \mu \mathrm{mol}\end{array}$ & $\begin{array}{l}\text { Inhaled dose } \\
\text { of ASA mg }\end{array}$ & $\begin{array}{l}\text { Cumulative dose } \\
\text { of ASA mg }\end{array}$ \\
\hline 1 & 0.1 & 1 & 1 & 1 & 0.18 & 0.18 \\
\hline 2 & 0.1 & 2 & 2 & 3 & 0.36 & 0.54 \\
\hline 3 & 0.1 & 5 & 5 & 8 & 0.90 & 1.44 \\
\hline 4 & 0.1 & 13 & 13 & 21 & 2.34 & 3.78 \\
\hline 5 & 1.0 & 4 & 40 & 61 & 7.20 & 10.98 \\
\hline 6 & 1.0 & 9 & 90 & 151 & 16.20 & 27.18 \\
\hline 7 & 2.0 & 11 & 220 & 371 & 39.60 & 66.78 \\
\hline 8 & 2.0 & 32 & 640 & 1011 & 115.20 & 181.98 \\
\hline
\end{tabular}

solution were inhaled every $30 \mathrm{~min}$ and FEV1 and FVC values were measured at 10,20 and $30 \mathrm{~min}$ after each dose. The provocation was interrupted when FEV1 had fallen $>20 \%$ from the postsaline baseline value, or if the strong extrabronchial symptoms (see below) occurred, as well as when the maximum cumulative dose of L-ASA had been reached (182 $\mathrm{mg}$ of ASA). After the completion of the test, spirometry was carried out every $15 \mathrm{~min}$ until the FEV1 value had returned to within $90 \%$ of the postsaline baseline value.

Bronchospastic reactions following either challenge were relieved by short-acting $\beta$-mimetics or by i.v. GCS (SoluMedrol; Pharmacia \& Upjohn, Puuts, Belgium). No severe or long-lasting reactions were observed which could require a longer hospitalization or treatment in the intensive care unit.

Spirometric values (FVC, FEV1) were measured on PNEUMO 2000 (abcMED, Poland) and nasal conductance (peak nasal inspiratory flow) was measured with a Youlten Peak Nasal Flow Meter (Clement Clarke International Ltd., London, UK).

\section{The criteria for the positive result of challenge proced-} ures

The provocation test was considered positive if FEV1 value decreased at least $20 \%$ from a postsaline baseline value, and/or if strong extrabronchial symptoms occurred. The most frequent extrabronchial symptoms were: rhinorrhoea, nasal congestion, redness of the face and the upper chest, ocular injection and/or periorbital swelling, nausea and stomach cramps.

These symptoms were scored on a five-step scale (0: no symptoms; 1: small intensity; 2: moderate intensity; 3 : strong intensity; 4: very strong intensity). The maximal possible score was 24. Extrabronchial symptoms were considered strong when a patient attained at least 12 score points.

In those patients in whom at least a $20 \%$ decrease in FEV1 during oral and/or inhaled test had occurred, the provocative dose of ASA causing a 20\% fall in FEV1 (PD20) was calculated and recorded as the PD20 ASA oral, and the PD20 ASA inhaled, respectively. The PD20 was derived by linear interpolation from the respective base 10 logarithm cumulated dose-response curves.

\section{Urinary excretion of leukotriene $E_{4}$}

In 31 patients with AIA, $\mathrm{LTE}_{4}$ excretion in urine was analysed by enzyme linked immunosorbent assay (ELISA; Cayman Chemicals, Ann Arbor, MI, USA), as reported by
KumLIn et al. [18], before, during and after the challenge with ASA and/or L-ASA. In oral challenge, the first urine sample was collected before the test, the consecutive samples every $2.5 \mathrm{~h}$ until the conclusion of the test. If the test was positive, a urine sample was also collected $2 \mathrm{~h}$ later. During placebo phase, the urine samples were collected in a similar manner. During the inhalation challenge the first urine sample was collected before the test, the second at the conclusion of the test; the third one $2 \mathrm{~h}$ later, if the result of the test was positive. Following placebo, the urine samples were collected before and at the conclusion of the test. The urine samples were centrifuged $(1,000 \times g$ per $10 \mathrm{~min})$ and the supernatant was frozen at $-70^{\circ} \mathrm{C}$ until processed.

\section{Statistical evaluation}

Statistical evaluation was carried out using a personal computer and Statistica ${ }^{\mathrm{TM}}$ software (Statsoft Inc., Tulsa, OK, USA). All PD20 values were log transformed before the analysis and descriptive statistics were expressed as geometric mean (GM) and percentage standard deviation (\% SD* GM; \% SD=sDlog transformed data). All other summary statistics were expressed as mean and standard deviation (SD).

As a result of outliers and non-normality of the data (Shapiro-Wilk W test) it was not possible to use the global parametric analysis of variance (ANOVA). So a MannWhitney U Rank Sum Test was used to compare two independent groups, a Wilcoxon Signed Rank Test was used for matched pair studies, and a Kruskal-Walis and a Friedman rank ANOVA were used for comparing several groups. The relationships between variables were studied with Spearman's R correlation coefficient. In all procedures the influence of outliers on statistical inference was checked by performing all tests with and without the observation suspected to be outlier. In order to statistically compare the sensitivity of both tests to the clinical diagnosis AIA the two-sided test was used.

\section{Results}

In patients with AIA the oral challenge tests, as measured by at least a $20 \%$ decrease in FEV1, were positive in 24 out of 35 patients. When strong extrabronchial symptoms were also used as a criterion, the positivity increased to 31 cases. The bronchial challenge tests were positive in 21 out of 35 cases, as measured by at least a $20 \%$ decrease in FEV1. In six additional patients the test could be considered positive when strong extrabronchial symptoms 
were taken into account. In one patient with ASA intolerance, the bronchial challenge test could not be performed, because of bronchial instability (positive placebo test). In the remaining four patients who had had positive oral challenges in the past, both oral and bronchial challenges were invariably negative during this study.

There were three patients in whom the results of the tests were discordant, oral tests were positive, but the bronchial ones were negative. Those patients were in a stable period of asthma and were on the same drugs during both procedures. In the first patient after the fourth dose of ASA (117 mg) a sudden $40 \%$ drop in FEV1 during the oral challenge occurred, but the inhalation test was negative twice. In two other patients oral challenge was considered positive on the basis of extrabronchial symptoms, while bronchial challenge was negative. In the first one, during the oral test, very strong symptoms from many organs developed suddenly; redness of the face and chest, nasal discharge, redness and itching of the eyes and the skin, nausea, stomach cramps, headache, anxiety and retrosternal pain with accompanied ST-segment elevation. The FEV1 value dropped only $18 \%$ from baseline. In the second subject, during the oral test, strong extrabronchial symptoms occurred (but mainly nasal).

The minimum value of PD20 ASA oral was $13 \mathrm{mg}$ of ASA, maximum value $410 \mathrm{mg}$ and GM $66.1 \mathrm{mg}$. The minimum value of PD20 ASA inhaled was $0.46 \mathrm{mg}$ of ASA, maximum was $176 \mathrm{mg}$ and GM was $4.93 \mathrm{mg}$. PD20 ASA inhaled was significantly lower than PD20 ASA oral ( $p=$ 0.000 ). There was no correlation between PD20 ASA oral and PD20 ASA inhaled (Spearman $\mathrm{R}=0.242, \mathrm{p}=0.304$ ).

During oral challenges no correlation was found between PD20 ASA and baseline postsaline FEV1 (Spearman $\mathrm{R}=0.030, \mathrm{p}=0.891$ ). Similarly, no correlation was found betteen PD20 ASA inhaled and baseline postsaline FEV1 values in inhaled challenges (Spearman $\mathrm{R}=0.138, \mathrm{p}=0.573$ ).

The possible effects of the chronic treatment with GCS on PD20 ASA values were analysed. Oral challenge tests were performed in seven patients, while they were receiving oral GCS (the dose varied from $2-10 \mathrm{mg}$ of prednisolone, mean value $5.9 \mathrm{mg}$ ), whereas the other 17 patients did not receive them. There was no statistically significant difference in PD20 ASA oral values between these two groups (Mann-Whitney $\mathrm{p}=0.775$ ). The patients who were treated with oral GCS during the inhaled challenge test $(n=5$, dose $1.25-10.0 \mathrm{mg}$, mean value $6.0 \mathrm{mg}$ of prednisolone) had slightly lower PD20 ASA inhaled values compared to those, who did not take oral GCS ( $\mathrm{n}=16$; unpaired t-test $\mathrm{p}=0.011$, Mann-Whitney $\mathrm{p}=0.069$ ).

\section{Provocation tests in acetylsalicyclic acid tolerant asthmatics}

During the oral challenge test only one asthmatic patient from the control group developed extrabronchial symptoms: itching and redness of the skin, nausea, abdominal pain, headache and sore throat. These symptoms were recorded as 12 score points; thus the test was considered positive on the basis of extrabronchial symptoms. Similarly, during the inhalation test, another asthmatic patient developed sufficiently strong extrabronchial symptoms to consider the test positive. In this particular case the rash on the face, headache, nausea and sore throat were observed.
The results of the statistical evaluation of the sensitivity, the specificity, the positive predictive value, the negative predictive value and overall accuracy of both challenge tests are presented in table 3 . The sensitivity of oral challenge was somewhat higher than the sensitivity of the bronchial challenge, but the difference did not reach statistical significance $(\mathrm{p}=0.18$, two-sided test). The results for 34 patients who participated in the study were analysed; one patient with the bronchial instability was excluded from the statistical evaluation.

\section{Urinary leukotriene $E_{4}$ excretion during oral and inhaled challenge procedure}

Analysis embraced 27 ASA-intolerant patients who underwent oral challenge tests, and 31 ASA-intolerant patients who completed bronchial challenge tests. There was no significant difference in baseline levels of $\mathrm{LTE}_{4}$ before the administration of placebo, ASA, or L-ASA. After placebo, administered either orally or by inhalation, there was no statistical difference in urinary levels of $\mathrm{LTE}_{4}$ in the consecutive samples. $\mathrm{LTE}_{4}$ increased significantly following both oral ( $\mathrm{p}=0.000$, Wilcoxon Matched Pairs Test) and inhaled ( $\mathrm{p}=0.01$, Wilcoxon Matched Pairs Test) challenge tests. The rise in $\mathrm{LTE}_{4}$ was higher following the oral, as compared to bronchial challenge tests $(\mathrm{p}=0.0001$, Wilcoxon Matched Pairs Test).

The urinary excretion of $\mathrm{LTE}_{4}$ during the oral challenges was also analysed in relation to the results of the tests. It was therefore analysed separately in 18 patients with positive test based on FEV1 fall, in five patients with positive results based only on strong extrabronchial symptoms, and in four patients with negative results of the tests. The highest rise in $\mathrm{LTE}_{4}$ was noted in subjects with severe

Table 3. - Comparison of sensitivity, specificity, positive predictive value, negative predictive value and overall accuracy in relation to the clinical diagnosis of acetylsalicylic acid-induced asthma during oral and inhaled challenges

\begin{tabular}{|c|c|c|c|c|}
\hline \multirow[t]{3}{*}{ Criterion } & \multicolumn{2}{|c|}{$\begin{array}{l}\text { Oral challenge } \\
\text { test }\end{array}$} & \multicolumn{2}{|c|}{$\begin{array}{l}\text { Inhaled challenge } \\
\text { test }\end{array}$} \\
\hline & \multicolumn{4}{|c|}{ Test considered positive } \\
\hline & $\begin{array}{l}\text { Fall in } \\
\text { FEV } 1 \\
>20 \%\end{array}$ & $\begin{array}{c}\text { Fall in } \\
\text { FEV1 } \\
>20 \% \\
\text { and/or } \\
\text { EBS }\end{array}$ & $\begin{array}{c}\text { Fall in } \\
\text { FEV } 1 \\
>20 \%\end{array}$ & $\begin{array}{c}\text { Fall in } \\
\text { FEV1 } \\
>20 \% \\
\text { and/or } \\
\text { EBS }\end{array}$ \\
\hline Sensitivity & 69 & 89 & 60 & 77 \\
\hline Specificity & 100 & 93 & 100 & 93 \\
\hline Positive predictive value & 100 & 97 & 100 & 96 \\
\hline Negative predictive value & 58 & 77 & 52 & 64 \\
\hline Overall accuracy & 78 & 90 & 72 & 82 \\
\hline
\end{tabular}

Data are presented as percentages. Sensitivity, true-positive tests results/all patients with the disease. Specificity, true-negative tests results/all patients without the disease. Positive predictive value, true-positive test results/all positive test results. Negative predictive value, true-negative test results/all patients with negative test results. Overall accuracy, true-positive and true-negative test results/all tests. FEV1: forced expiratory volume in one second; EBS: extrabronchial symptoms. 


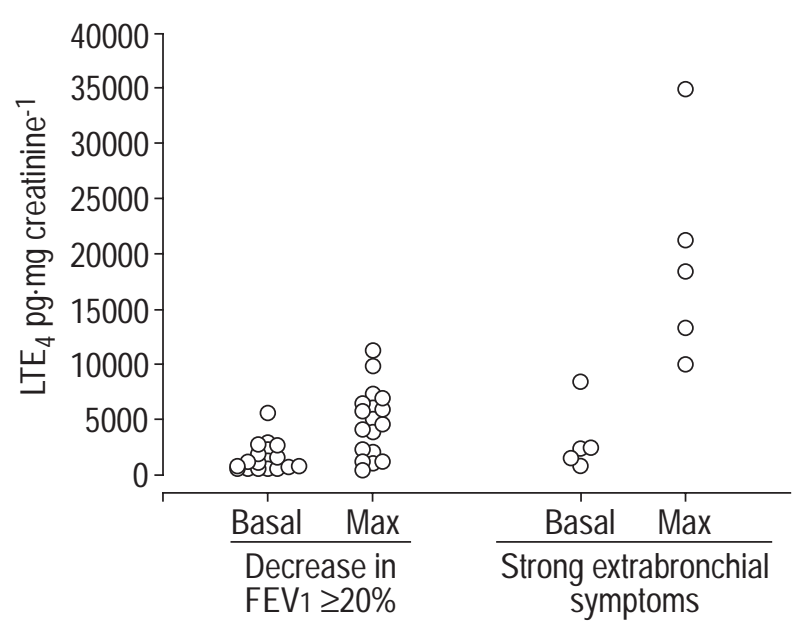

Fig. 2. - Urinary leukotriene (LT)E $\mathrm{E}_{4}$ levels during oral challenges. Max: maximum value following challenge; FEV1: forced expiratory volume in one second. Individual values are shown.

extrabronchial symptoms (nasal, ocular, skin, etc.; $\mathrm{p}=0.04$; fig. 2). Smaller increases in $\mathrm{LTE}_{4}$ levels occurred during oral challenges with typical bronchospastic reactions with at least a $20 \%$ decrease in FEV1 $(\mathrm{p}=0.005)$. $\mathrm{LTE}_{4}$ excretion did not change following the negative oral challenges in ASA-intolerant asthmatics $(\mathrm{p}=0.46)$.

Similar analysis was carried out for bronchial challenges: in 18 patients with FEV1 fall $\geq 20 \%$; in six patients with positive test based on strong extrabronchial symptoms; and in six patients with negative results. The analysis showed a similar tendency as during oral challenges, but no statistical significance was reached.

There was no correlation between PD20 oral and maximal $\mathrm{LTE}_{4}$ urinary levels $(\mathrm{p}=0.34)$, and between PD20 inhaled and maximal urinary $\mathrm{LTE}_{4}$ levels $(\mathrm{p}=0.39)$.

\section{Discussion}

There is no reliable in vitro test for diagnosing ASA intolerance. The authors have examined the value of the modified protocols of both oral and inhaled (bronchial) challenges in patients with AIA. The methodology of the oral provocation tests differ between clinical centres $[3,4$, 7-14]. Oral challenge tests with ASA were introduced systematically into clinical practice in the early 1970s [14], and in consecutive years they were validated by STEVENSON and Simon [3] and Dahlen and ZetTerström [8]. They mimic the natural exposure to the drug and are commonly accompanied not only by bronchial, but also by extrabronchial and general symptoms. For many years, a 4-day protocol has been used in the authors' Department [14]. The main difference between the previously used and the present oral challenge protocol was the actual duration of the test (4 days previously and 2 days in the present study). Cumulative doses of ASA also varied (in the previous protocol $900 \mathrm{mg}$ and presently $500 \mathrm{mg}$ ).

The inhalation test for the diagnosis of ASA intolerance was introduced into a clinical practice by BIANCO et al. [7] in 1977. In the following years it was used by: SchMitzSchumann et al. [12], Sakakibara et al. [24], Philips et al. [11] and DAhLEN and Zetterström [8]. The tests differed in the consecutive doses of L-ASA, the intervals sep- arating them and in the total cumulative dose of ASA administered. Only one study compared the oral with the inhalation challenges in 22 subjects suspected of ASA intolerance (17 of them were asthmatics) [8]; there is, however, insufficient information concerning sensitivity and specificity of the bronchial tests, as well as their positive and negative predictive value compared with the oral challenge tests.

The current authors developed similar procedures for carrying out both oral and inhalation provocation tests with ASA and L-ASA, respectively, with the cumulative doses of the drug increasing in a geometric progression. This allowed, for the first time, the calculation of the PD20 ASA oral and PD20 ASA inhaled values. Both of the tests were also shortened to a 2-day procedure. The intervals between the consecutive oral ASA doses were long enough, so no severe bronchospastic reactions were observed that would necessitate intensive treatment.

The tests were always preceded by placebo challenges, administered in the same manner as ASA upon the following day. This made the test somewhat longer, but excluded the patients with bronchial instability. It was found to be essential to carry out this placebo challenge, since the ASA-sensitive asthmatics can have significant variations in FEV1 over several hours during the ASA challenge test, when FEV1 manoeuvres are repeated many times. Until recently in most clinical centres only a few saline breaths were administered as placebo just before the inhalation of L-ASA [7, 8, 11, 12, 25], or one capsule containing lactose just before ASA administered in oral challenge [10]. The oral cumulative dose of ASA, $500 \mathrm{mg}$, used in this study, administered during 1 day, seems to be high enough to detect existing hypersensitivity to ASA, and is similar to the one used by other authors $[3,8]$. In the applied procedure the authors tried to avoid severe sideeffects following the ASA administration, as well as the possible desensitization to ASA [9].

The authors modified the inhalation protocol of DAHLEN and ZETTERSTRÖM [8] by using an almost five times higher cumulative dose of ASA. No important side-effects were observed, although the frequency of extrabronchial symptoms was more common than reported by other investigators $[3,8,11,12,25]$. In two patients FEV1 fell by $>20 \%$, but only after the inhalation of the higher doses of ASA (PD20 ASA oral=73 mg and $180 \mathrm{mg}$ respectively); they would have been misdiagnosed, if the higher doses were not applied. The reversibility of bronchoconstriction was almost the same during both tests in the study. In subjects who reacted to ASA inhalation the intensity of the reaction was comparable to the one following the oral challenge.

In three cases there was a discordance between the results of oral and bronchial challenge tests. The first subject responded to a relatively high dose of ASA during the oral test. The doses of ASA used the bronchial test were, perhaps, too small to provoke bronchial reaction, since only $10-20 \%$ of the inhaled ASA possibly reaches the bronchial tree. In two other patients the oral challenges with ASA were positive only on the basis of the extrabronchial symptoms. It could not be expected that much smaller doses of ASA administered during the inhaled challenge test would provoke a $20 \%$ decrease in FEV1 or extrabronchial symptoms. In those three cases both the past 
history and the results of the oral challenges were positive, thus the results of the inhalation tests were falsely negative.

In one case the oral test was positive (PD20 oral $=26 \mathrm{mg}$ ASA) following the inhalation of placebo, so the test with L-ASA was not performed. After 1 month, the inhalation test was attempted again with the same result. Thus, there are some patients in whom bronchial challenge cannot be performed, because of the nonspecific bronchial hyperreactivity. A short-time repeatability study of oral and bronchial ASA challenges was not carried out.

In four asthmatics who had positive oral challenge tests over the last $10 \mathrm{yrs}$, both oral and inhaled tests were negative during the present study. In all of them both challenges were repeated within $2-3$ weeks; both challenges were negative. These four patients were on low-dose prolonged oral corticotherapy, and also received budesonide (400-1200 $\mu \mathrm{g}$ per day). The effect of the corticosteroid treatment on the results of oral challenges with ASA was the subject of a previous study [23]. NiZANKOWSKA and SzCEKLIK [23] found that oral and inhaled GCS administered for at least 10 days could attenuate or inhibit the bronchospasm induced by ASA. However, the doses of GCS used by the patients in the present study were much smaller than in the subjects studied in the past and did not exceed $5 \mathrm{mg}$.

It is likely that administration of increasing doses of ASA might have induced ASA tolerance (desensitization). It would be possible to exclude the desensitization by way of giving one single cumulative dose of ASA (500 mg). The authors refrained from doing so for safety reasons. The observations suggest that in some patients intolerance to ASA may disappear after several years, which was also reported by other authors [3].

Oral PD20 did not correlate with inhaled PD20. Different routes of administration, different absorption rates from bronchi and gastrointestinal tract, as well as different metabolism of ASA in these two tissues might explain these results.

In ATA subjects only the extrabronchial symptoms occurred on two occasions; one during the oral test and one during the inhalation challenge. In both cases, respiratory symptoms were absent and mainly skin reactions such as redness and itching of skin, nausea and stomach cramps were observed. ASA can elicit a variable scope of adverse effects, which do not constitute AIA $[3,26]$.

The results of this study confirm the previous observations that urinary $\mathrm{LTE}_{4}$ levels increase following ASA challenge in AIA patients [18, 27-31]. Unexpectedly, the highest increases were noted in patients with severe extrabronchial symptoms who did not develop a $20 \%$ decrease in FEV1. Perhaps, some organs other than the lungs and bronchi were the source of LTs. The most common extrabronchial symptoms were observed in the nose. Several authors have reported LT increase in nasal lavage after ASA challenge in AIA $[15,19]$. KowALSKI et al. [32] also noticed that intranasal challenge with ASA lead to an increase in the concentration of eosinophils and eosinophil cationic protein in ASA-sensitive patients. Eosinophils in turn seem to be the main source of cysteinyl-LTs in the nasal tissue. The effectiveness of anti-LT drugs in attenuation of nasal symptoms in AIA patients also points to cysteinyl-LTs as the important local mediators [33]. A smaller rise in urinary $\mathrm{LTE}_{4}$ occurred during the challenges with typical bronchial adverse reactions (with at least a $20 \%$ decrease in FEV1). There were no increases in urinary $\mathrm{LTE}_{4}$ excretion during the negative oral and bronchial challenges, and when placebo (oral or bronchial) was administered.

In summary, modified oral and bronchial provocation tests were used with aspirin and their diagnostic value in aspirin intolerance compared. Both tests had similar specificity, but the oral one showed somewhat higher sensitivity, although the difference did not reach the level of statistical significance. The major advantage of the bronchial challenge was, however, the shorter time required to carry out the challenge. The inclusion of extrapulmonary symptoms beside the pulmonary function tests enhanced the diagnostic value of both procedures. Bronchial sensitivity to aspirin determined as the provocative dose causing a $20 \%$ fall in forced expiratory volume in one second, showed no relationship to pulmonary function at baseline. No correlation was observed between aspirin the provocative dose causing a $20 \%$ fall in forced expiratory volume in one second, determined by the oral compared to the inhalation route. Rise in urinary leukotriene $\mathrm{E}_{4}$ following aspirin challenge confirmed the diagnosis of aspirininduced asthma. The highest leukotriene $\mathrm{E}_{4}$ response in the presence of extrabronchial symptoms may suggest the participation of tissues other than the lung in leukotriene $\mathrm{E}_{4}$ release in urine.

\footnotetext{
Acknowledgements. The authors would like to take this opportunity to express their gratitude to R. Dworski, Vanderbilt University, Nashville, TN, USA, for the analysis of urinary leukotriene $\mathrm{E}_{4}$ levels.
}

\section{References}

1. Szczeklik A, Gryglewski R, Czerniawska-Mysik G. Relationship of inhibition of prostaglandin biosynthesis by analgesics to asthma attacks in aspirin-sensitive patients. BMJ 1975; 1: 67-69.

2. Lee TH. Mechanism of aspirin sensitivity. Am Rev Respir Dis 1992; 145: 34-36.

3. Stevenson DD, Simon RA. Sensitivity to aspirin and nonsteroidal anti-inflammatory drugs. In: Allergy: Principle and Practice, Middleton E, Reed CE, Ellis EF, Adkinson NF, Yunginger J, Eds. St Louis, Missouri. Mosby-Year Book Inc. 1993; 2: 1747-1765.

4. Szczeklik A, Stevenson D. Aspirin induced asthma: Advances in pathogenesis and management. $J$ Allergy Clin Immun 1999; 104: 5-13.

5. Nizankowska E, Duplaga M, Bochenek G, Szczeklik A. Clinical course of aspirin-induced asthma; results of AIANE. In: Eicosanoids, Aspirin and Asthma. Szczeklik A, Gryglewski R, Vane J, Eds. New York, NY, USA, Marcel Dekker Inc., 1998; pp. 451-470.

6. Kowalski ML, Sliwinska-Kowalska M, Igarashi Y, White MV, Wojciechowska B, Kaliner MA. Nasal secretion in response to acetylsalicylic acid. J Allergy Clin Immunol 1993; 91: 580-598.

7. Bianco S, Robuschi M, Petrigni G. Aspirin induced tolerance in aspirin-asthma detected by a new challenge test. J Med Sci 1977; 5: 129-130.

8. Dahlen B, Zetterström O. Comparison of bronchial and 
per oral provocation with aspirin in aspirin-sensitive asthmatics. Eur Respir J 1990; 3: 527-534.

9. Szczeklik A, Nizankowska E. Pharmacological agents in bronchial provocation tests. In: Methods in asthmology. Allegra L, Braga PC, Dal Negro R, ed. Berlin, Germany, Springer Verlag, 1993; pp. 253-264.

10. Bianco S, Robuschi M, Petrigni G. Aspirin sensitivity in asthmatics. BMJ 1981; 282: 146.

11. Phillips GD, Foord R, Holgate S.T. Inhaled lysine-aspirin as a bronchoprovocation procedure in aspirin-sensitive asthma: its repeatability, absence of a late-phase reactions, and the role of histamine. J Allergy Clin Immunol 1989; 84: 232-241.

12. Schmitz-Schumann M, Schaub E, Virchow C. Inhalative Provocation mit lysin-azetylsalizylsaure bei analgeticaasthma-syndrom. Prax Pneumol 1982; 36: 17-21.

13. Milewski M, Mastalerz L, Nizankowska E, Szczeklik A. Nasal provocation test with lysine-aspirin for diagnosis of aspirin-sensitive asthma. J Allergy Clin Immunol 1998; 5: 581-586.

14. Szczeklik A, Gryglewski RJ, Czerniawska-Mysik G. Clinical patterns of hypersensitivity to nonsteroidal antiinflammatory drugs and their pathogenesis. $J$ Allergy Clin Immunol 1977; 60: 276-284.

15. Ferreri NR, Howland WC, Stevenson DD, Spiegelberg HL. Release of leukotrienes, prostaglandins and histamine into nasal secretion of aspirin sensitive asthmatics during reaction to aspirin. Am Rev Respir Dis 1988; 137: 846-854.

16. Holgate ST, Bradding P, Sampson AP. Leukotriene antagonists and synthesis inhibitors: new directions in asthma therapy. J Allergy Clin Immunol 1996; 98: 1-13.

17. Israel $\mathrm{E}$, Fischer AR, Rosenberg MA, et al. The pivotal role of 5-lipoxygenase products in the reaction of aspirinsensitive asthmatics to aspirin. Am Rev Respir Dis 1993; 148: 1447-1451.

18. Kumlin M, Stensvad F, Larsson L, Dahlen B, Dahlen SE. Validation and application of a new simple strategy of measurements of urinary leukotriene $\mathrm{E}_{4}$ in humans. Clin Exp Allergy 1995; 25: 467-479.

19. Picado C, Ramis I, Rosello J, et al. Release of peptide leukotrienes into nasal secretions after local instillation of aspirin in aspirin-sensitive asthmatic patients. Am Rev Respir Dis 1992; 145: 65-69.

20. Szczeklik A, Sladek K, Dworski R, et al. Bronchial aspirin challenge causes specific eicosanoid response in aspirin sensitive asthmatics. Am J Respir Crit Care Med 1996; 154: 1608-1614.
21. Cowburn AS, Sladek K, Soja J, et al. Overexpression of leukotriene $\mathrm{C}_{4}$ synthase in bronchial biopsies from patients with aspirin-intolerant asthma. J Clin Invest 1998; 101: 1-13.

22. Sanak M, Simson HU, Szczeklik A. Leukotriene $\mathrm{C}_{4}$ synthase promotor polymorphism and risk of aspirininduced asthma. Lancet 1997; 350: 1599-1600.

23. Nizankowska E, Szczeklik A. Glucocorticosteroids attenuate aspirin-precipitated adverse reaction in aspirin-intolerant patients with asthma. Ann Allergy 1989; 63: 159-164.

24. Sakakibara H, Suetsugu S, Saga T, et al. Bronchial hyperresponsiveness in aspirin-induced asthma by inhalation test with water solution aspirin. J Jap Thor Soc 1988; 26: 275-283.

25. Pawtowicz A, Williams W, Davies B. Inhalation and nasal challenge in the diagnosis of aspirin-induced asthma. Allergy 1991; 46: 405-409.

26. Grzelewska-Rzymowska I, Schmidt M, Rozniecki J. Urticaria/angioedema-type sensitivity to aspirin and other nonsteroidal anti-inflammatory drugs. Diagnostic value of anamnesis and challenge test with acetylsalicylic acid. J Invest Allergol Clin Immunol 1992; 2: 191-195.

27. Christie PE, Tagari P, Ford-Hutchinson AW, et al. Urinary leukotriene $\mathrm{E}_{4}$ concentrations increase after aspirin challenge in aspirin-sensitive asthmatic subjects. Am Rev Respir Dis 1991; 143: 1025-1029.

28. Christie PE, Tagari P, Ford-Hutchinson AW, et al. Urinary leukotriene $\mathrm{E}_{4}$ after lysine-aspirin inhalation in asthmatic subjects. Am Rev Respir Dis 1992; 146: 1531-1534.

29. Oosaki R, Mizushima Y, Mita H, Akiyama K, Kobayashi $\mathrm{M}$. Urinary leukotriene $\mathrm{E}_{4}$ and 11-dehydrotromboxane $\mathrm{B} 2$ in patients with aspirin-sensitive asthma. Allergy 1997; 52: 470-473.

30. Sladek K, Szczeklik A. Cysteinyl leukotriene overproduction and mast cell activation in aspirin-provoked bronchospasm in asthma. Eur Respir J 1993; 6: 391-399.

31. Westcott JY, Smith HR, Wenzel SE, et al. Urinary leukotriene $\mathrm{E}_{4}$ in patients with asthma. Am Rev Respir Dis 1991; 143: 1322-1328.

32. Kowalski ML, Grzegorczyk J, Wojciechowska B. Intranasal challenge with aspirin induces cell influx and activation of eosinophils and mast cells in nasal secretion of ASA-sensitive patients. Clin Exp Allergy 1996; 26: 807-814.

33. Dahlen B, Nizankowska E, Szczeklik A, et al. Benefit from adding 5-lipoxygenase inhibitor Zileuton to conventional therapy in aspirin intolerant asthmatics. $A m J$ Respir Crit Care Med 1998; 157: 1187-1194. 